\title{
Selected Journals in Library and Information Sciences
}

\author{
Beverly P. Lynch
}

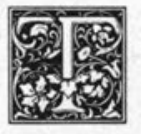

his article continues the series of reviews of journals published in the field of library and information science. Although it appears under a byline, the reviews are a project of the librarians of the University of Illinois at Chicago. Each review is signed with the initials of the librarian who prepared it. ${ }^{1}$

Bulletin of Bibliography. Westport, Conn.: Meckler Publishing. V.1, no.1 (Apr. 1897), quarterly, $\$ 45$ a year. ISSN 0190 745X. Continues Bulletin of Bibliography and Magazine Notes with v.36 (1979).

In its eighty-six years of continuous publication, this journal has shown variations in title and publisher. Bulletin of Bibliography addresses a wide range of "topics in the humanities and social sciences ... of scholarly and general interest which contain bibliographical material not accessible through published sources" (scope note in each number). Editor Nancy Jean Melin has narrowed this focus somewhat toward the strictly scholarly since assuming the editorship in 1982. She emphasizes the acquisition of "out of print and elusive materials as well as of highly specialized subject areas," together with "the philosophic aspects of developing bibliographies including the matter of bibliographic citation and indexing, as well as problems of access to specialized periodicals and collections" (Bulletin of Bibliography, v.39, March 1982, p.3). Thus far the backlog of articles accepted prior to her editorship has prevented any discernable change in direction.

Bibliographies may be of primary and/or secondary sources, depending on the author's aim and the scope of the bibliography. They are generally introduced by biographical or critical sketches and, in the case of persons, a photograph of the subject. Annotations are usually included unless the number of entries is prohibitive. The fact that these bibliographies are new to print makes this an invaluable tool for research libraries. The infrequency of letters criticizing or augmenting the bibliographies indicates that the editorial board of scholars in the various disciplines covered has an impressive record of demanding high-calibre scholarship.

Examination of the articles in volumes 38 to the latest shows a strong emphasis on the humanities, particularly Englishlanguage literature, which accounts for forty-three of sixty titles, or 71.6 percent. Foreign literature claims another four titles, or 6.6 percent. The remaining titles in history, political science, anthropology, geography, art, philosophy and religion make up 1 percent to 5 percent by discipline only. A cursory examination of three previous volumes did not show a significantly different orientation. Among the subjects covered in this sample were Ford Madox Ford, Vietnam War literature, Joan Didion, Anne Tyler, James Dickey, travel literature (1949-78), Arthurian legends, Reinhold Niebuhr, Pio Baroja, Sacco and Vanzetti, and twentieth-century witchcraft.

Regular features of earlier volumes that now appear sporadically include a photograph and biographical sketch of a prominent librarian or bibliographer-v.8 (1914) through v.24 (1964)-and the section

1. John Cullars, Lori Goetsch, Frank Immler, Louis A. Schultheiss, Patricia Tegler, Stephen E. Wiberley, Jr. 
"Births, Deaths, and Magazine Notes," which listed new, changed, or discontinued serials titles. Occasional book reviews have always appeared, but this is not a major feature. A cumulative index from 1897 to 1975 is separately available. - J.C.

\section{Computer Equipment Review. Westport,} Conn.: Meckler Publishing. V.1, no.1 (Jan.-June 1979), biannual; rate varies between $\$ 85$ and $\$ 150$ per year, depending upon subscriber classification. ISSN 0728-260X.

Intended for executives and office managers in organizations large enough to profit from some level of office automation, this journal should also be of interest to managers in all but the smallest libraries.

This review is based on a single issue, v.4, no.1 (July-Dec. 1982), which deals with multifunctional office systems. It begins with an introduction stating the purpose of the issue and a list of the manufacturers and specific systems to be reviewed. The introduction is followed by a very well written status report on the kinds and capabilities of existing systems and the technologies involved. The remainder of the issue is devoted to a detailed examination of systems from ten different manufacturers, selected as examples of the current state of the art. In many cases, more than one system is presented per manufacturer.

Evaluations of individual systems are clearly presented and illustrated with excellent photographs. The writing is clear and concise. A general knowledge of computer terminology is assumed, however, and probably is necessary for full comprehension of reports.

Unfortunately, journals of this kind are quickly dated by constant changes in the field. Although excellent at the time of publication, they would not be an accurate reflection of state of the art a year later. Nevertheless, this is a valuable publication and one that should be checked before investing in computer hardware for library or business use.-L.A.S.

Database: The Magazine of Database Reference and Review. Weston, Conn.: Online,
Inc. V.1, no.1 (Sept. 1978), quarterly, \$56 per volume. ISSN 0162-4105.

Database magazine grew out of Online, according to publisher Jeffrey Pemberton, as a place to "publish the in-depth articles on database searching that we can't fit into Online." Pemberton conceived Database as a magazine "to help you search better," with its focus on database contents and search techniques and strategies.

Over the six years of its existence, Database has remained essentially that. Each quarterly issue contains approximately six feature articles with six columns and special features. The articles are typically database and system reviews, or discussions of search techniques and applications. Some of the articles are of a highly specialized nature and likely to be of interest to a limited number of readers. Typically, each issue contains a few articles with broader appeal.

Even more than the feature articles, the columns and special features provide useful suggestions on improving search technique and keeping up with new developments in online searching. Despite changes in columns over the years, quality has remained high. Most of the columns focus on the practical aspects of online searching, specifically techniques for improving the quality of search results, tips on keeping up with developments in the field, reviews of database publication and documentation, and news from the field. A regular column by Pemberton, "The Linear File," discusses what he sees as the major issues facing the online industry. Since Pemberton is usually at least one step ahead of his readers, his ruminations make for provocative reading.

Database does an excellent job of covering the nitty-gritty of online searching while still providing food for thought. It remains a key publication in the field.P.T.

International Journal of Oral History. Westport, Conn.: Meckler Publishing. V.1, no.1 (Feb. 1980), three issues yearly, $\$ 40$ per volume. ISSN 0195-6787.

Although the first oral history program in the United States was founded in 1948, not until 1980 did the field's first dedicated 
journal, International Journal of Oral History, appear. More than half of the typical issue's seventy-five pages are devoted to two or three articles covering philosophy and methods of oral history or reporting historical research that used oral history sources. These articles are solid contributions and international in scope. These, combined with three to five perceptive book reviews, give librarians a good sense of the leading problems in oral history and of the scholarship that oral history collections support. Most issues also have one equipment review, an important feature.

Two other regular sections, "Recent Works of Note" and "News and Notes," raise questions. It is often unclear why the recent works of note are noteworthy. Some entries whose titles have no apparent relevance to oral history have their relationship to the field explained by a brief annotation. Other entries, which need annotations, lack them. Librarians, who have the special responsibility to acquire finding aids that give intellectual control over oral history sources, will observe that, except for v.4, no.1, an average of only two or three such aids are listed per issue. There are usually fewer than five pages of news, normally six or seven items, half from the United States. This seems remarkably little for a triannual of international scope. The paucity of listings of finding aids and of news makes one wonder if the editors have not yet established an adequate network to gather such information or if oral history is a field of relatively low activity.

This is a valuable publication for librarians active in oral history. Its bibliographic section and especially its cost- 78 percent above that of the average history journallessen its worth for others.-S.W.

\section{Online: The Magazine of Online Information}

Systems. Weston, Conn.: Online, Inc.

V.1, no.1 (Jan. 1977), bimonthly, \$78 per volume. ISSN 0146-5422.

Publisher Jeffery Pemberton in the first issue of Online expressed an interest in having a letters column that was "lively, interesting. . . and fun." Seven complete volumes later it appears that he has succeeded in publishing an entire magazine that meets those criteria. As publisher and president of Online, Inc., Pemberton has had unusual flexibility and editorial freedom to create the magazine that he envisioned. He has exercised that freedom by publishing a trade magazine rather than a scholarly journal and by emphasizing the practical over the research-oriented.

Each issue contains as many as eight feature articles and eight to ten columns and special features. All contributions maintain a consistently upbeat, innovative, and pragmatic tone, and are written by and for the practitioner. In addition to the usual articles on improving search techniques, Online focuses on the management, training, and economics of search systems. The feature articles often describe interesting approaches to common problems, and offer excellent suggestions for improving both search technique and search service management.

Current columns include "Printout," a regular column of "news from around the world of online information," "Management Outpost," "European Notes," "Document Delivery," and a bookreview section. Despite changes in subject and editorship, the quality of the columns has been consistently high. The one constant throughout Online's seven volumes has been "Inverted File," a column written by Pemberton. The column occasionally features guest editors, but typically consists of either Pemberton's opinions on events in the online industry or his "crystal ball gazings." These contributions are always entertaining and informative, and often provocative. Recent issues have included an attack on Mead Data Central's purchase of the New York Times Information Bank, an analysis of online trends in the 1980s, and an assessment of the role of the search analyst in the future. Pemberton's columns exemplify Online's greatest strength. In a field that is moving too fast for most of us, Online has managed not only to keep up with changes but to look to the future. For example, recent developments in end-user searching and in applying microcomputer technology to database searching have been thoroughly discussed in the pages of Online. The articles on these topics can serve as tutorials 
for those who are unfamiliar with the state of the art.

To date, Online has achieved an exemplary record of anticipating, reporting, and responding to advances in the online field. In doing so, it has become essential reading for all librarians interested in this area.-P.T.

\section{Online Review: The International Journal of} Online Information Systems. Medford, N.J.: Learned Information. V.1, no.1 (Mar. 1977), bimonthly, $\$ 70$ per volume. ISSN 0309-314X.

Online Review is unique among online system publications in that it is both scholarly in tone and international in perspective. Over the seven years of its publication, it has maintained an unusually consistent quality and approach. Each bimonthly issue (it moved from a quarterly publication schedule with v.5, no.1, 1983) typically consists of a ten- to fifteen-page news section, a calendar, several book reviews, and four or five feature articles. Columns on online user groups and search techniques, which appeared in earlier volumes, have since been dropped. Beyond that, few format or editorial policy changes are apparent.

The feature articles reflect the journal's international approach. Authors are most frequently from Western Europe or the United States, with occasional representation from Australia or Canada. Other areas of the world are largely unrepresented.

The articles themselves are an interesting mix of database and system evaluations or comparisons, trend analyses, discussions of the search process, and descriptions of individual systems or practices throughout the world. The researchbased articles frequently employ sophisticated methodologies, although for the most part they can be easily read by any online professional.

More practically oriented pieces, such as price comparisons, command charts, and database analyses, have immediate application for the online searcher. The quality of the articles is consistently high, and the occasional lapse can be easily forgiven, given the usual quality that is maintained.
The news section provides information on the online industry, new databases, system changes, industry surveys, personnel changes, and other timely events in the online world. The focus is generally on information from the United States and Western Europe and is typically reported in an informative, unbiased fashion.

Despite high-quality scholarship and informative news, there is still something lacking with Online Review. All of its virtues cannot fully make up for the journal's rather bland tone and its distance from its readers. This seems largely due to the editor's low key, almost invisible, presence. For example, the journal's editorial policies or statement of purpose have never appeared in its pages and can only be determined indirectly.

Relatively few letters to the editor have been published, and those that have are rarely controversial or thoughtprovoking. More letters from readers, and occasional columns or comments from the editor or editorial board, might enliven the publication. Problems in tone, however, cannot mar the fact that Online Review is an unusually solid journal. It has already made a significant contribution to the field with its unique emphasis on scholarly international online literature.P.T.

Special Collections. New York: Haworth Pr.

V.1, no.1 (Fall 1981), quarterly, $\$ 95$ per volume. ISSN 0270-3157.

Each issue of this serial focuses upon collections of materials in a developing, or otherwise problematical, subject area in the arts, sciences, social sciences, or humanities. Each is edited by an expert in the field surveyed and follows a common organizational pattern: a summary of the growth of collecting in the field, descriptions of several important individual collections, an article on some aspect of bibliographic control, a directory to collections, and reviews of recent publications relevant to the subject area. The series editor, Lee Ash, also provides reviews of titles of interest to the broader field of special librarianship.

The four issues that have so far appeared cover theatre and performing arts, 
biochemistry, gerontology, and science fiction. Each serves its purpose reasonably well, with knowledgeable curators demonstrating the strengths and varieties of their collections. Inevitably, a project designed to appeal to such disparate sorts as librarians, collectors, students, scholars, and dealers, will appeal as a whole to few. Some inconsistencies occur: style and tone vary even within an issue, and the thrust of the most provocative issuebiochemistry - is toward collections development rather than special collections.

More seriously, the curious and provoking production problems that plague some other Haworth publications are evident in Special Collections. Nine quarters have passed since the autumn of 1981, but only four issues have emerged. Why such delays? The fifteen articles of the first issue occupy 166 pages; three issues later, the second "double issue" (v.2, no. 1/2) also has fifteen articles in 181 pages. What legitimately constitutes a "double" issue? Finally, in excusing the first double issue (v.1, no. 3/4), the series editor alludes to the issue's larger content. In fact, there are eleven articles in 171 pages. Worse, the next page informs the reader that "due to manufacturing limitations four papers originally scheduled" for the issue would appear in future issues of another $\mathrm{Ha}$ worth Press publication! This raises serious and regrettable questions concerning editorial control and publishing integrity. Surely, the distinguished editors and contributors, not to mention subscribers spending $\$ 95$, deserve better than this.

Probably only libraries that support library schools would want a series subscription. Wisely, Haworth has also marketed the two most recent issues as hardbound monographs at \$29.95.-F.I.

WLW Journal. Berkeley, Calif.: Women

Workers. V.1, no.1 (Jan. 1976), quarterly, $\$ 4$ per volume (\$2 sample issue). ISSN 0272-1996.

WLW Journal's subtitle, News/Views/Reviews for Women and Libraries, accurately describes this lively publication. Each issue is full of information and opinion valuable to anyone interested in resources on women's issues and concerns.

The journal's primary contribution to library literature is as a selection tool for women's studies and women-related subjects. Several regular features, such as "Media Review," "Framed," "Records," "Finders Sleepers," and "Continuing Guide to Women's Serials," provide straightforward and often lengthy reviews of fiction and nonfiction, nonprint media, periodicals, and pamphlets. Materials selected for review are predominantly publications of alternative presses and organizations that are unlikely to be reviewed elsewhere.

Other regular features are the columns "Highlighting Women," which focuses on women's collections around the country, "Up Your Wages," and "Women in Librarianship: Research," which discusses literature on the status of women library workers. Each issue includes one or two lengthy articles or bibliographic essays on topics such as parenting, management, science fiction, and women's history. The editorial tone is unapologetically feminist and viewpoints range from commentaries on librarianship to more global issues, such as nuclear war. Thus the journal, through both its reviews and its articles, provides an important alternative perspective not found in other library journals.

As a news publication, WLW Journal provides information on Women Library Workers and similar groups around the nation. Early issues show a strong West Coast slant, but the publication has developed a more national perspective in its coverage of events and its selection of writers and reviewers.

The publication is a helpful resource for both collection development and research in women's issues, particularly as those issues relate to librarianship. Its low subscription price makes it a bargain for academic and public librarians.-L.G.

Women in Libraries. Newark, N.J.: American Library Assn. Social Responsibilities Round Table Feminist Task Force. V.1 (1971-72), five times/year from September to June, $\$ 4$ for individuals, $\$ 6$ for 
institutions prepaid, and $\$ 8$ for institutions invoiced.

This eight-page newsletter of the Feminist Task Force reports primarily on women's activities and concerns within the American Library Association. The September 1983 issue, for example, has stories on business transacted by various women's groups in Los Angeles and on programs at the ALA conference that were sponsored by these groups. Other information in a typical issue might be announcements on women's activities around the country as they relate to librarianship or scholarship, information on publications on women's issues, government activities, calls for papers, reviews, conferences, and brief summaries of research.

The news and reviews are timely and thorough, making the publication essential for anyone interested in staying informed on women's programs within ALA and in librarianship in general. The newsletter is helpful to women's studies librarians and researchers for the information it provides on conferences and recent research. It is more suited for an individual than an institutional collection.-L.G. 


\section{You can Tell Our Coverage By Our Cover}

\section{But There's So Much More Inside}

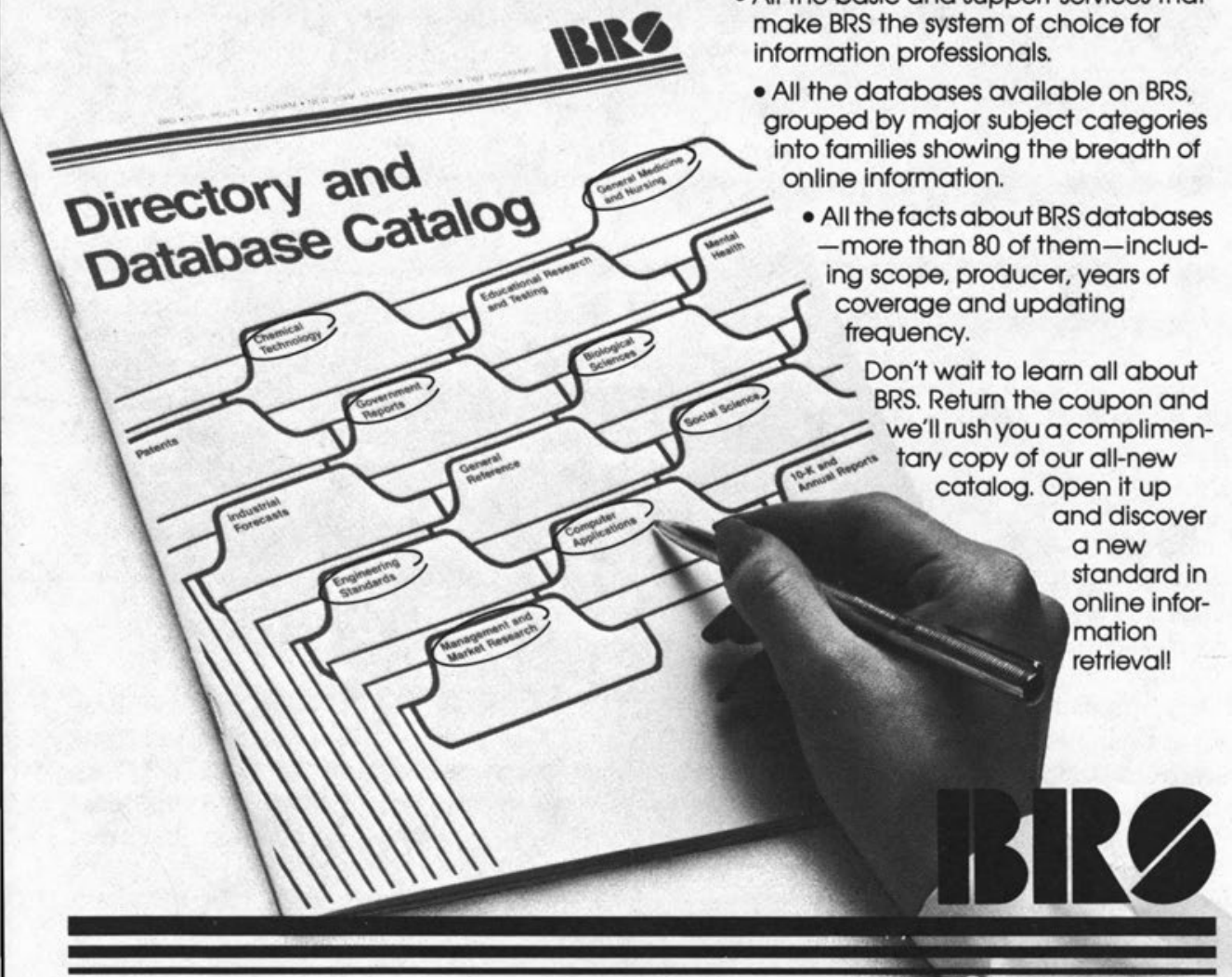

- All the basic and support services that make BRS the system of choice for

- All the databases available on BRS grouped by major subject categories into families showing the breadth of online information.

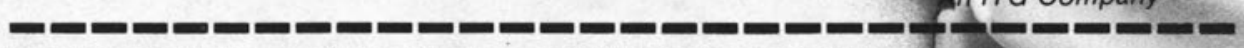
Send me my free copy of the new BRS Database Catalog. NAME

COMPANY/INSTITUTION

CITY STATE

TELEPHONE 